\title{
Correction to: Prognostic factors in patients with glioblastoma multiforme: focus on the pathologic variants
}

\author{
Ehsan Alimohammadi ${ }^{1}$ (1) Seyed Reza Bagheri ${ }^{1} \cdot$ Alireza Sadeghsalehi $^{1} \cdot$ Parisa Rizevandi $^{1} \cdot$ Zahra Rezaie $^{1}$. \\ Alireza Abdi ${ }^{1}$
}

Published online: 16 July 2019

๑) Belgian Neurological Society 2019

\section{Correction to: Acta Neurologica Belgica https://doi.org/10.1007/s13760-019-01171-x}

Unfortunately, the third author name was incorrectly published in the original publication. The complete correct name should read as follows.

Alireza Sadeghsalehi

The original article has been updated.

Publisher's Note Springer Nature remains neutral with regard to jurisdictional claims in published maps and institutional affiliations.

The original article can be found online at https://doi.org/10.1007/ s13760-019-01171-x

Ehsan Alimohammadi hafez125@gmail.com

Seyed Reza Bagheri seyedrb@gmail.com

Alireza Sadeghsalehi alireza.sadeghsalehi@gmail.com

Parisa Rizevandi parisar@gmail.com

Zahra Rezaie zahrarez@gmail.com

Alireza Abdi alirezaab@gmail.com

1 Imam Reza Hospital, Kermanshah University of Medical Sciences, Kermanshah, Iran 